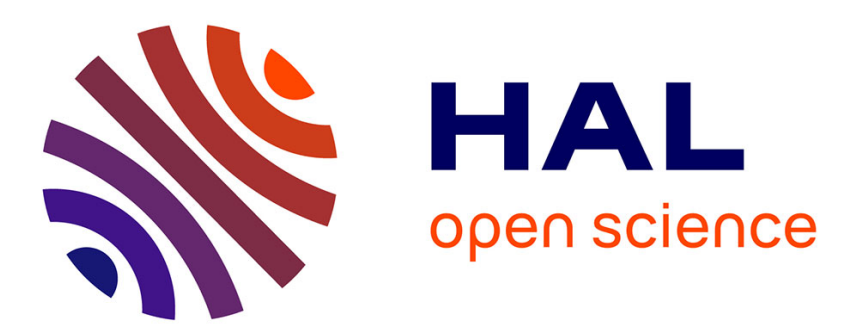

\title{
Variation in primate decision-making under uncertainty and the roots of human economic behaviour
}

Francesca de Petrillo, Alexandra Rosati

\section{To cite this version:}

Francesca de Petrillo, Alexandra Rosati. Variation in primate decision-making under uncertainty and the roots of human economic behaviour. Philosophical Transactions of the Royal Society B: Biological Sciences, 2021, 376 (1819), pp.20190671. 10.1098/rstb.2019.0671 . hal-03151858

\section{HAL Id: hal-03151858 \\ https://hal.science/hal-03151858}

Submitted on 30 Mar 2021

HAL is a multi-disciplinary open access archive for the deposit and dissemination of scientific research documents, whether they are published or not. The documents may come from teaching and research institutions in France or abroad, or from public or private research centers.
L'archive ouverte pluridisciplinaire $\mathbf{H A L}$, est destinée au dépôt et à la diffusion de documents scientifiques de niveau recherche, publiés ou non, émanant des établissements d'enseignement et de recherche français ou étrangers, des laboratoires publics ou privés. 
PHILOSOPHICAL TRANSACTIONS B

royalsocietypublishing.org/journal/rstb

Review

Cite this article: De Petrillo F, Rosati AG.

2021 Variation in primate decision-making

under uncertainty and the roots of human

economic behaviour. Phil. Trans. R. Soc. B 376:

20190671.

https://doi.org/10.1098/rstb.2019.0671

Accepted: 14 August 2020

One contribution of 17 to a theme issue 'Existence and prevalence of economic behaviours among non-human primates'.

\section{Subject Areas:}

cognition, evolution, behaviour

\section{Keywords:}

non-human primates, risk, economic behaviour, individual variation, cooperation

\section{Author for correspondence:}

Francesca De Petrillo

e-mail: francesca.de-petrillo@iast.fr

\section{Variation in primate decision-making under uncertainty and the roots of human economic behaviour}

\author{
Francesca De Petrillo0,2,3 and Alexandra G. Rosati ${ }^{3,4}$
}

\author{
${ }^{1}$ Institute for Advanced Study in Toulouse, Toulouse, Occitanie, France \\ ${ }^{2}$ Unità di Primatologia Cognitiva e Centro Primati, Istituto di Scienze e Tecnologie della Cognizione, \\ Consiglio Nazionale delle Ricerche, Roma, Lazio, Italy \\ ${ }^{3}$ Department of Psychology, and ${ }^{4}$ Department of Anthropology, University of Michigan, Ann Arbor, MI, USA \\ (iD) FDP, 0000-0002-1289-2881; AGR, 0000-0002-6906-7807
}

Uncertainty is a ubiquitous component of human economic behaviour, yet people can vary in their preferences for risk across populations, individuals and different points in time. As uncertainty also characterizes many aspects of animal decision-making, comparative research can help evaluate different potential mechanisms that generate this variation, including the role of biological differences or maturational change versus cultural learning, as well as identify human-unique components of economic decision-making. Here, we examine decision-making under risk across non-human primates, our closest relatives. We first review theoretical approaches and current methods for understanding decision-making in animals. We then assess the current evidence for variation in animal preferences between species and populations, between individuals based on personality, sex and age, and finally, between different contexts and individual states. We then use these primate data to evaluate the processes that can shape human decision-making strategies and identify the primate foundations of human economic behaviour.

This article is part of the theme issue 'Existence and prevalence of economic behaviours among non-human primates'.
Electronic supplementary material is available online at https://doi.org/10.6084/m9.figshare. c.5230732.

\section{Introduction}

Decisions about uncertainty are central to many aspects of human economic behaviour, from choices between assets with different levels of risk in financial markets, to choices about the investment of energy and time in foraging versus hunting activities in subsistence societies. Yet humans also show great variation in their responses to risk across groups, individuals and contexts. For example, there are differences in typical risk propensities across different nations $[1,2]$ and small-scale societies [3-5]. Within populations, there can be stable interindividual differences that vary by gender $[6,7]$, personality $[8,9]$ or stage in the life-course [9-13]. Finally, individuals can also flexibly shift strategies across time, showing different preferences for risk in different contexts [14,15] or depending on their own internal states [16-19]. Understanding the causal mechanisms generating this variation, as well the downstream consequences of different decision strategies, is, therefore, a crucial issue in economics, psychology and biology.

How and why do individuals make different kinds of choices? Studies of human decision-making first indicate that some variation in strategies can stem from an individual's (or population's) particular cultural or environmental experiences-and may even constitute adaptive, learned responses to local environments $[5,12,20]$. For example, various proposals highlight how market experiences [5], familiarity with particular cultural norms [1,21] or socialization practices [6,21] may drive differences in decision-making across groups or individuals. Alternatively, other processes that are not experience-dependent may also underpin aspects of this variation, such as genetic differences between 
individuals [22-24], the hormonal status of men versus women $[18,19]$ or the maturation of neural systems recruited in decision-making over development [25-28]. Finally, studies of economic outcomes show how variation in strategies can have profound effects on people's economic success, and consequently, on macroeconomic dynamics $[2,9,13]$. For example, more risk-averse individuals are less likely to engage in entrepreneurial activities and invest in stocks, and countries with higher aggregate risk aversion have lower productivity $[9,13]$.

Yet this work also highlights how it can be difficult to parse out the causes and consequences of different strategies, because human economic behaviour is shaped by a complex interplay of both biological influences that are shared with other species, and cultural norms and institutions that are unique to humans [29]. Since other animals must also make assessments of value and cost-benefit trade-offs concerning rewards like food or mates, but are not embedded in rich cultural contexts like humans, comparative research can help adjudicate different proposals for why humans show different preferences across populations, individuals and contexts. This approach can disentangle shared biological contributions from cultural or human-specific features of decision-making, as well as provide a crucial line of insight into not just the economic consequences of different decision strategies (such as in foraging contexts), but also the specific evolutionary contexts that promote different kinds of strategies.

Here, we examine the evolutionary roots of human economic behaviour by examining shared core features of decision-making under uncertainty across primates. While uncertainty broadly encompasses both risk (or probabilistic variation in outcomes) and ambiguity (or lack of knowledge of the associated probabilities) [30], we primarily address risky choice, given that it has been a greater focus of comparative research to date. We examine primates as they are our closest evolutionary relatives, and further exhibit several relevant parallels in their cognition and neurobiology [31,32], social behaviour [33], sex differentiation [34] and development [35,36] —yet also lack human-specific forms of culture and economic markets. We first provide an overview of theoretical frameworks for decision-making under risk from economics, psychology and biology. Then, we synthesize empirical methods for measuring animal decision-making. We then focus on variation in non-human primate choices (i) across species and populations; (ii) across individuals according to personality traits, sex and developmental stage; and finally (iii) within individuals according to internal states and external contexts. We use this empirical evidence to identify which features of human decision-making are more widely shared with other primates, versus which are novel and thus potentially culturally malleable. Finally, we highlight new directions for future waves of comparative research that can help us evaluate current hypotheses for the origins of human economic behaviour.

\section{Modelling decision-making under risk}

Predicting how humans and non-human animals make decisions under risk is a major question in economics, psychology and biology. Although classical economic theories suggest that decision-makers should focus on the average expected value provided by different options, people often exhibit a strong aversion to risk [37,38]. For example, when presented with choices between a certain option with a reliable outcome (such as getting \$10) and a risky option that can vary (such as a
$50 \%$ chance of winning $\$ 20$ ), people overall prefer the certain option-even though both provide the same average payoff [38]. One model aiming to explain such examples of risk aversion is the expected utility theory [38]. Here, rational actors should prefer options that offer the highest subjective utility (which may not align exactly with external markers of value), weighted by the probability of obtaining that outcome [38]. While this is a straightforward and testable idea, it turns out that people rarely conform to its predictions. Prospect theory, therefore, aims to better capture this type of real-world behaviour, by distinguishing how people assign subjective value to options from how they judge probabilities $[37,38]$. Here, preferences for options depend on whether they are perceived as gains or losses [37]. Since people dislike negative changes in the status quo (losses) more than they like an equivalent increase (gain), this model accounts for several observed biases in choice, such as framing effects where people are risk-seeking for losses but risk-averse for gains [37].

By contrast to these approaches from economics, biologists have developed models that share many of the same features with a key difference: biologists assume decision-makers act to maximize their biological fitness [39,40]. These models generally formalize foraging decisions in which animals make choices about different foods, and consider how different patterns of food intake may affect fitness. A dominant model is risk sensitivity theory, which highlights that the relationship between calories and fitness outcomes is not one-to-one-paralleling ideas from prospect theory about the nonlinear relationships of money and utility. Here, an animal's optimal response to variance in foraging payoffs depends on its resource budget $[40,41]$ : pursuing a predictable outcome may be advantageous for a small animal in a positive energetic state (i.e. when there is a concave relationship between the energy gain and fitness), but risk-seeking is better for the same animal in a negative energetic state (when there is a convex relationship) as this may be the only pathway to survival [41]. This provides a biological explanation of how reference points-here rooted in an animal's energetic state-may affect risky choice [42,43].

However, it is important to note that all of these approaches struggle to account for some salient aspects of variation in decision preferences seen in humans and animals. While both economic and biological theories may address how context [37,43], including the type of goods at stake [44], impacts individuals' risk propensity, there is still no framework for understanding the origin of inter-individual or populationlevel differences in choice strategies-such as why there may be stable risk-seeking phenotypes displayed by some individuals but not others [32]. Similarly, humans and non-humans sometimes behave according to the predictions of risk sensitivity theory [41,45], yet this view is also not always successful at predicting individuals' risky choices [41]. For example, in larger-bodied animals-where short-term energetic requirements do not represent a significant threat to survival-riskseeking behaviours may emerge more often when individuals are in a positive energetic state [46]. Understanding the cause of such variation across populations and individuals is, therefore, a crucial step for building more predictive theoretical models.

\section{Measuring animal decision-making}

Given that non-humans cannot talk, read or use money, a key issue in comparative decision-making is how to measure 


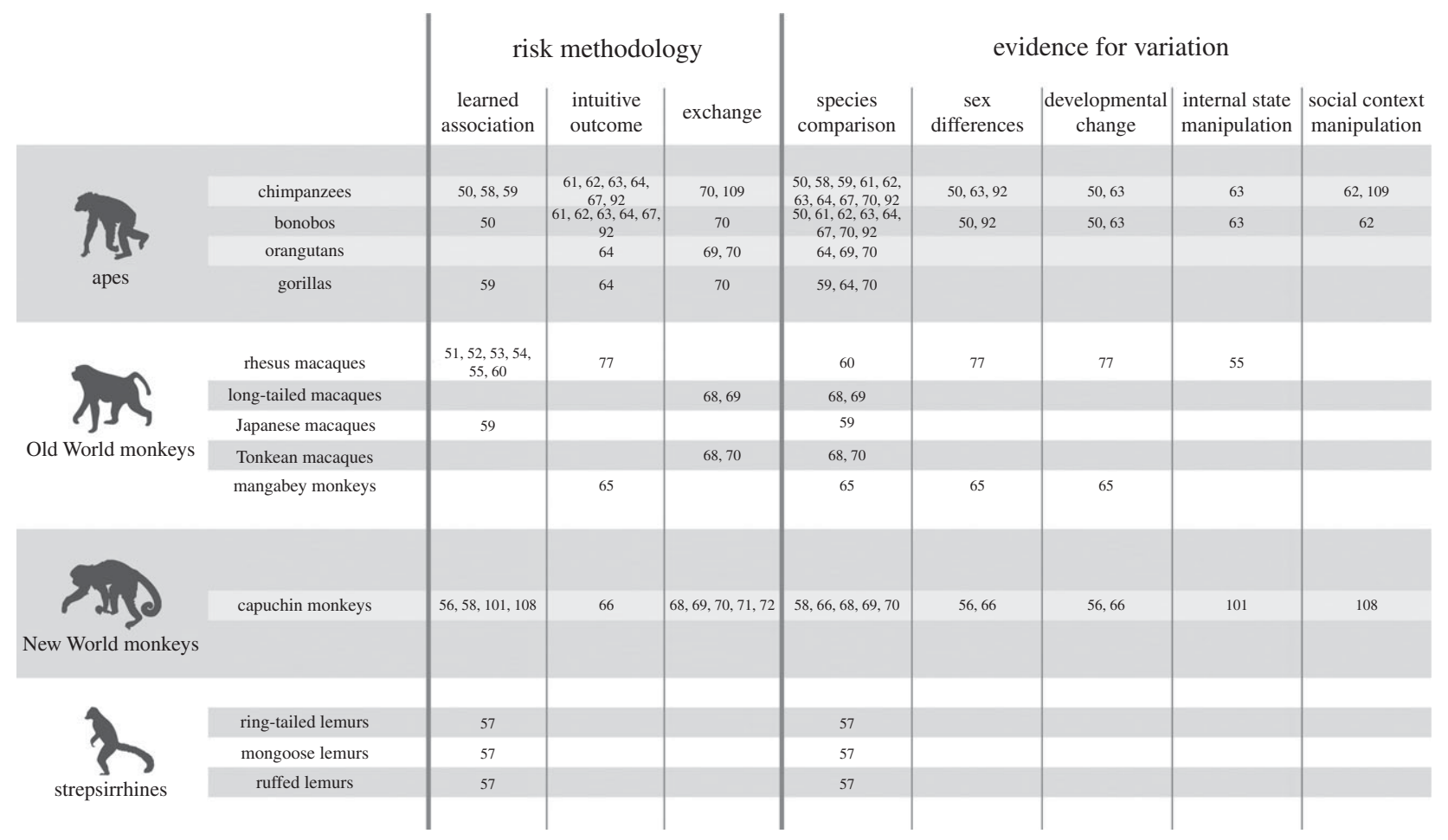

Figure 1. Empirical data on primate decision-making under risk. Phylogenetic distribution of current primate data across species indicating types of tasks, comparisons across species and individual variation between sexes and by age; and finally state and context manipulations; note that there is a lack of comparisons across populations or by personality traits in studies of primate risk preferences. We report the references for studies in each category (see electronic supplementary material, table $S 1$ for full breakdown of results by study).

animal preferences. Human preferences can be measured in experiments involving choices between different options, often involving monetary rewards [47], or by looking at a person's 'revealed preferences' by observing their real-life consumer behaviour [48]. Most animal studies, in contrast, use a series of experiential foraging decisions about consumable rewards such as food to infer preferences [49]. Within this general methodological approach, several different kinds of tasks have been developed to probe primate responses to risk (figure 1 and electronic supplementary material). This variation in tasks is important for then interpreting different patterns of variation across studies using different methodological approaches.

One common setup involves learned associations where animals are trained to understand different payoffs associated with a 'safe' option yielding a constant food reward, and a 'risky' option yielding a reward that varies probabilistically around the mean. For example, individuals might learn that a cue like the colour or location of a container (or similar cues on a computer) signals different reward distributions. Animals can then choose between two options, often involving the same average payoff, to assess if they are sensitive to risk. For example, they may choose between a safe option that always provides three pieces of food, and a risky option that offers one or five pieces with $50 \%$ likelihood. Thus, a preference for the safe option indicates risk aversion, a preference for the risky option indicates risk-seeking, and indifference indicates risk neutrality [49]. In other cases, the payoff contingencies may be adjusted across trials to test how animals modulate their choices when expected values shift. In many studies, animals first gain experience with reward contingencies in a learning phase to then examine stabilized choice preferences in a test phase [50-57], whereas other studies focus on how animals learn about the value and variance of different outcomes [58,59]. This basic kind of paradigm has been used with multiple primate species, including chimpanzees (Pan troglodytes) [50,58,59], bonobos (Pan paniscus) [50], gorilla (Gorilla gorilla) [59], rhesus macaques (Macaca mulatta) [51-55], Japanese macaques (Macaca fuscata) [59], capuchin monkeys (Sapajus apella) [56,58] and several lemur species (Lemur catta, Eulemur mongoz, Varecia rubra) [57], in some cases with comparisons with humans [58,60].

A second methodology focuses on intuitive outcomes, examining how animals respond more spontaneously to different situations that simulate risky outcomes without explicit training on cues signalling reward distributions. For example, one reward may be hidden under one of several containers out of the animal's view, such that the number of possible containers indicates the probability that the reward is under any particular cup. This risk option can then be contrasted with a safe or known alternative to assess animals' responses to risk when both the amount of the reward and the probability of obtaining it vary [61-66]. Another intuitive task involves decisions about quality or type of food rewards [61-63]: an intermediately preferred food type is placed in one container, whereas either a high-value or low-value type of food (e.g. a banana versus a cucumber) is hidden in another out of the animal's view, to assess if it gambles on possibly receiving a preferred food type. To date, this basic kind of paradigm has been used to test chimpanzees [61-64], bonobos [61-64], orangutans (Pongo abelii) [64], gorillas [64], mangabeys (Cercocebus torquatus torquatus) [65] and capuchins [66], with comparisons to humans [67].

A final approach uses exchange tasks where animals learn to exchange tokens or food with a human. For example, animals may be initially provided with a food item, and then can exchange it for the opportunity to win a larger, equal or smaller food reward seen in one of several containers [68-70]. If the animal chooses to exchange, the content of one container is 
randomly selected to simulate risk (similar to the intuitive tasks described above). Other tasks involve the exchange of tokens for food rewards to simulate a primate 'market economy' $[71,72]$. In particular, primates are given a budget of allotted tokens they can distribute across experimenters with different exchange rates. Exchange paradigms involving either token or food trading have been used to test the four great apes [69,70], Tonkean macaques (Macaca tonkeana) [68,70], long-tailed macaques [68,69] and capuchins [68-72].

\section{Variation in animal decision strategies}

Human risk propensity is characterized by wide variation at both population and individual level, including differences across cultures [1-5], genders [6,7], ages [9-13] and contexts [14-19]. To understand this variation, we review empirical studies of non-human primates' preferences and discuss how they inform the origins of human economic preferences.

\section{(a) Variation across species}

Human populations can exhibit differences in risk propensity, so some proposals have highlighted that different strategies may be favoured in different kinds of environments. For example, some work highlights that experience with markets may promote risk-seeking responses [3,5], whereas other work argues that subsistence populations are actually relatively risk-seeking [4]. More generally, this evidence shows how human cultural groups may innovate different kinds of decision-making strategies to navigate their local environment. Comparisons of different animal species can provide a complementary test of these adaptive explanations. The comparative method is a powerful tool for understating the evolutionary history of different traits by comparing species with different socioecological characteristics [73], so testing different species on closely matched decision-making tasks can assess how dietary ecology or social systems may promote more risk-seeking versus risk-avoidant strategies.

Current evidence indicates that some primate species are more risk-averse or more risk-seeking than others when tested on matched tasks (figure 1 and electronic supplementary material), even when sharing similar foundational cognitive skills for understanding numerosity [74] and probability [75-77]. For example, bonobos are relatively more risk-averse than chimpanzees in the same context [50,61-63]. Feeding ecology may ultimately explain this variation: chimpanzees and bonobos are sister species, but show key differences in their ecological niche. Whereas chimpanzees exploit more seasonally variable and widely distributed fruit resources and exhibit higher rates of risky hunting, bonobos have more access to terrestrial herbaceous vegetation, an abundant and reliable food source-differences in natural history that predict a higher tolerance for risk in chimpanzees than bonobos [78]. A comparison of all the four great ape species aligns with this view: chimpanzees and orangutans were both relatively risk-seeking, whereas bonobos and gorillas were relatively risk-averse [64]. While orangutans feed on highly seasonal fruits and engage in costly extractive foraging behaviours, more like chimpanzees $[79,80]$, gorillas rely on consistent leaves and roots food resources and do not use tools in the wild [81], more like bonobos.

Further evidence that natural history can shape decisionmaking strategies comes from instances of evolutionary convergence, where distantly-related species that face similar ecological problems evolve similar traits. For example, capuchin monkeys extensively use tools, hunt a variety of prey (including some that can be dangerous) and feed on variable food resources [80,82]—more like the socioecological features seen in chimpanzees. Comparisons of capuchin and ape decision-making in matched contexts found that capuchins and chimpanzees are both more risk-seeking than their closer relatives [82]. Indeed, this pattern of convergence may hold across other aspects of decision-making, as chimpanzees and capuchins monkeys also exhibit a greater preference for larger, delayed rewards in inter-temporal choice tasks compared with their closer relatives [82]. From an evolutionary perspective, future rewards are generally inherently uncertain [49], such that species that consume foods that entail long delays (such as search times) while foraging in nature may also need to tolerate the risk intrinsic to these situations.

Overall, these findings show that matched comparisons can hone in on a biological 'signature' of species-specific cognitive adaptations for decision-making, and identify the evolutionary contexts that promote different strategies [78,82]. Variation in animal decision-making strategies across populations provides complementary evidence to studies of human populations $[3,5,12]$ finding that differences in population-level risk propensity can represent adaptive response to the challenge posed by their natural environment. While that line of work has often focused on how decision depends on culture or market integration [3-5], comparative studies further identify specific relevant characteristics of the ecological world that promote different responses to risk: animals living in more seasonally variable environments, and that feed on more temporally and spatially heterogenous food resources, show a greater preference for risk [78].

\section{(b) Variation across populations within a species}

A related question is whether primates exhibit population-level differences as a result of experiences in their own lifetime, rather than of species-typical traits. This kind of experience-based proposal is an important explanation for human population-level variation $[5,20]$ that intersects with ideas about how culture shapes risk propensity [3-5]. Importantly, comparisons of different species living in similar environments, such as in zoos or sanctuaries, often equate the experiences of different species, thus minimizing the possibility that detected species differences are a direct response to their experienced habitats as might be the case in the wild. Yet a growing body of evidence also documents marked geographical variation within a given species in some kinds of behaviours, such as tool use in wild chimpanzees, orangutans and capuchins. This variation may reflect social learning, but also may reflect individual problem-solving in response to local environmental challenges such as food scarcity or availability of relevant materials [80]. This suggests there may also be population-level differences in underlying decision-making preferences, given the important role of such preferences in foraging behaviours.

To date, there have been no comparisons of whether primate populations differ in risk preferences. Some data do suggest that divergent risk preferences between chimpanzees and bonobos are detectable across different populations (e.g. in zoos versus sanctuaries) tested with different methodologies [50,61-64], suggesting this is relatively stable difference. Yet other preferences can differ across 
populations. For example, capuchins from an Atlanta laboratory were markedly more patient in a delay of gratification task than those from a Rome laboratory [83], raising the possibility that differences in their experiences might shape preferences. Along these lines, one relevant question is whether primate populations that have been trained to use tokens [71-72,84] exhibit different risk preferences from those who have not. Such comparisons can test hypotheses on the drivers of human economic preferences, since the degree of market integration is proposed to influence human populations $[5,20]$. Thus, within-species population comparisons using the same methods are an important issue for future work on animal decision-making.

\section{(c) Trait differences across individuals}

Human preferences also vary across individuals within the same population: some individuals are more risk-seeking, whereas others are consistently risk-averse. An individual's willingness to take risks can predict decisions about the labour market, investments and even migration [13], so personality and genetic factors that shape risk-seeking or risk-averse profiles are an important focus of research. In humans, some personality traits do appear to be related to risk propensity $[8,9,85,86]$ : sensation-seeking [85], impulsivity [86] and extraversion [8] are all associated with greater risk-seeking, while conscientiousness [8] and neuroticism [8] are associated with risk aversion. These propensities may stem from heritable genetic variation, as monozygotic twins show more similar responses to risk than do dizygotic twins [22,23], and genetic variants in the serotoninergic and dopaminergic neurotransmitter pathways predict individual preferences [24]. This work, therefore, has highlighted the specific psychological and neurobiological mechanisms that shape risk responses across individuals.

Unfortunately, few studies have directly addressed whether primates show comparable individual variation. A key issue is that many relevant non-human populations (where controlled experiments are possible) are fairly small. However, some work does hint at shared neurobiological mechanisms with humans: genetic variants in the dopamine transporter predicted individual differences in inter-temporal choice in capuchins [87], and reducing serotonin levels via tryptophan depletion increased risk preference in rhesus macaques [53]. A crucial next step will then be characterizing individual variation in risk propensity in larger samples. For example, a study of 37 chimpanzees and bonobos [63] comparing these species also found a fair amount of inter-individual variation in risk propensity, as individual bonobos chose the risky option in between 6 and $67 \%$ of trials, and chimpanzees between 11 and $100 \%$. Other studies have successfully tested larger samples of a single species on decision-making tasks [88]. By relating this kind of variation in risk propensity to individuals' specific personality traits or genetics, it will be possible to assess the degree to which humans and other primates share these mechanisms for risky choice.

\section{(d) Sex differences}

Humans also exhibit variation in risky decision-making by gender: women are less willing to take risks than men across several contexts [6,7]. This has implications for real-world economic behaviour, as women are less likely to work under variable-payment schemes in the labour market and make safer investments [7-9]. Some proposals ascribe this difference to cultural learning about gender roles [6], whereas other explanations emphasize that neurobiological differences in brain regions associated with decision-making $[27,28]$ or variation in hormones like testosterone [19] can also drive gender differences. Since other primates lack human-like gender socialization, but exhibit strong parallels in terms of sexual differentiation in the brain and body [36], they can help distinguish between these mechanistic explanations.

Primates do show several well-characterized sex differences in behaviour that reflect females' and males' optimal behavioural strategies-and are plausibly related to risk attitudes. For example, female chimpanzees tend to be less gregarious and engage in more extractive foraging than males, reflecting the greater impact of food competition on female reproductive success, whereas male chimpanzees engage in more risky aggression and hunting than females $[89,90]$. Along the same lines, male capuchins spend more time on the ground foraging for exposed large invertebrates and small vertebrates, whereas females remain a few metres above the ground searching for embedded invertebrates [91]. More generally, females may be more sensitive to maintaining a consistent energetic state owing to the costs of pregnancy and lactation [34]. This line of reasoning suggests that males would exhibit a greater tolerance for economic risk than females.

Yet several studies have compared risk preferences across male and female primates, and consistently failed to find any appreciable sex differences (figure 1 and electronic supplementary material). This includes studies of chimpanzees [50,63], bonobos [50], capuchins [56,66] and mangabeys [65]. While this may be in part due to small sample sizes, other studies did detect sex differences in decision-making in comparable samples. For example, a study of 40 apes found that males were more susceptible to a framing manipulation than females [92]. Similarly, a study of 16 capuchins found that females could delay gratification more than males [93]. Thus, current evidence suggests that there may be at best subtle sex differences in psychological risk propensity in primates, despite stark differences in some forms of behavioural risk-taking. This accords with a broader set of findings indicating that primates only sometimes exhibit sex differences in cognition paralleling those in humans [33,94,95]. Overall, this evidence suggests that gender differences in risky choice observed in humans may be primarily due to socialization experiences, not to biological differences that are shared with other species, given the weak or absent evidence for parallel effects in non-human primates.

\section{(e) Developmental change over the life-course}

Human risk preferences can also change over the lifespan: adolescents tend to be more risk-prone than either children or adults [25,26], and older adults show a mixed pattern of increasing risk aversion or preservation of risk attitudes depending on task demands [9-13]. These developmental shifts in risk preference have important macroeconomic consequences: aging societies invest less in risky stocks and entrepreneurial activities, and show higher support for conservative savings and investment strategies that impact societal productivity $[9,13]$. Several proposals argue that age-related changes in the neural circuits underlying decision-making drive these shifts both during maturation in adolescence $[25,26]$ and during aging [96]. Yet generational effects, such 
as differences in educational attainment or experience of historical events like the Great Depression, may also underlie some apparent age differences $[97,98]$.

Other primates also exhibit relatively slow life histories like humans [99], and studies of comparative cognitive development indicate that animals can exhibit developmental change in spatial memory [100] and gaze-following [33] that mirror those in humans. However, most studies of primate risk preferences to date have not found major age-related changes (figure 1 and electronic supplementary material). This is the case for chimpanzees [50,63], bonobos [50,63], mangabeys [65] and capuchins [56,66]. As with sex differences, it is important to note that this work has generally involved small sample sizes with limited age ranges, so a crucial step is to examine populations with greater age variation. Moreover, given that adolescence and old age are points in the lifecourse that show major shifts in humans, these periods warrant special attention in non-humans. For example, a study examining probability inference in 80 rhesus monkeys ranging from juvenility to old age found that all age groups distinguished statistically unlikely from statistically likely outcomes [77], suggesting that older macaques do not show the same declines in probabilistic inference seen in older humans [96]. Thus, current work suggests that non-humans may not show all the same age-related changes seen in humans, but is also fairly limited in scope.

\section{(f) State-dependent choice}

Individuals can show different responses to risk across situations: the same person's choices may depend on their internal energetic state, transitory fluctuations in hormones or their emotional state at the moment of the decision. For example, people may change their responses to risk depending on whether they are hungry [45]. Differences in levels of hormones like testosterone and cortisol can also impact risk propensity: whereas increasing cortisol drives greater risk aversion [18] testosterone increases risk-seeking [19]. Finally, even transient emotional states affect risk propensity: while more positive emotions can increase risk-taking, negative states, such as sadness, decrease people's preference for risk [16,17].

Recent work suggests that some of these processes are shared between humans and other primates. First, chimpanzees, bonobos and capuchins show several features of human-like emotional responses to risky decision-making [63,101] (figure 1 and electronic supplementary material). In particular, they showed more indicators of negative emotional states-such as negative vocalizations, scratching or throwing a tantrumwhen they gambled and lost compared with when they gambled and won or played it safe. In addition, apes and capuchins spontaneously attempted to 'switch' their initial choices after gambling and losing - that is, they attempted to revise their choice and select the forgone option, a behaviour they rarely showed in response to other outcomes. In this way, choice switching might be a behavioural indicator of 'regret' [16].

By contrast, studies examining the influence of the hormonal state on primate economic decision-making are scant, which is surprising given the evidence that cortisol and testosterone shape many aspects of primate behaviour [102]. Direct manipulations of primates' internal states to test causal relationships are also lacking, which is also surprising given the great theoretical attention devoted to the impact of energy budget on risk propensity [41]. To date, only one study has conducted an energy manipulation in primates, and it found that rhesus macaques become more risk-seeking when their energy level is higher [55]_paralleling wild observations that larger-bodied primates engage in more risk-prone hunting in times of resource plenty, the opposite of the pattern seen in small animals [46]. Overall then, while there have not been many investigations into the impact of the internal state on primate risk choice, current data do suggest some psychological or physiological mechanisms potentially shared with humans.

\section{(g) Context-dependent variation}

Decision preferences can also be affected by external factors. Several aspects of context can shape human choice, including the specific currency of the reward at stake $[67,103]$ and the larger social context. Importantly, these processes intersect with the state-dependent effects described in the prior section: social context or reward currency may affect risk propensity by impacting internal emotional or hormonal states. That is, differences in internal states may in fact stem from cues in the external environmental context.

Here, we focus primarily on social context, as this is a crucial evolutionarily relevant context. In particular, humans exhibit both extensive and flexible cooperation compared with other primates [104], and this dependence on social exchange strategies may have shaped our responses to risk. In fact, people do tend to be more risk-seeking when other people are present than when alone [14] or in competitive contexts [15]. This may in part reflect a fundamental distinction concerning how humans respond to social versus non-social risk: people are less willing to gamble on the trustworthiness of another person compared with an identical non-social risk, a phenomenon called betrayal aversion [105]. This increased sensitivity to social risks may arise from uniquely human emotions and motivations used in cooperative contexts, such as reciprocity or theory of mind skills [106]. Indeed, huntergatherers, who are an important model of how humans have lived for most of our species' existence, appear to buffer the high risks associated with a diet focused on high-value but difficult to obtain foods by engaging in extensive food sharing [107]. Thus, studies of non-human primates can help disentangle how human-specific patterns of decision-making facilitate human cooperative economic behaviours like exchange, trade and investment.

While other primates do not engage in exchange or food sharing to the extent that humans do, they are also highly social and must constantly make decisions about whether to cooperate or compete with others. These situations inherently pose problems involving risk because decision-makers must choose between courses of action where another individual's behaviour creates variability in payoffs. Accordingly, there is some evidence that social context may impact non-human risk choices too (figure 1 and electronic supplementary material). For example, both chimpanzees and bonobos are more riskseeking following a competitive interaction, compared with a neutral or a playful one [62]. Conversely, capuchins become more risk-averse in the presence of a conspecific than when alone [108]. Finally, chimpanzees were more averse to uncertainty stemming from another individual who can choose to reciprocate, versus a non-social probabilistic device [109].

More generally, several studies have adapted human economic games for use with primates, including the ultimatum 


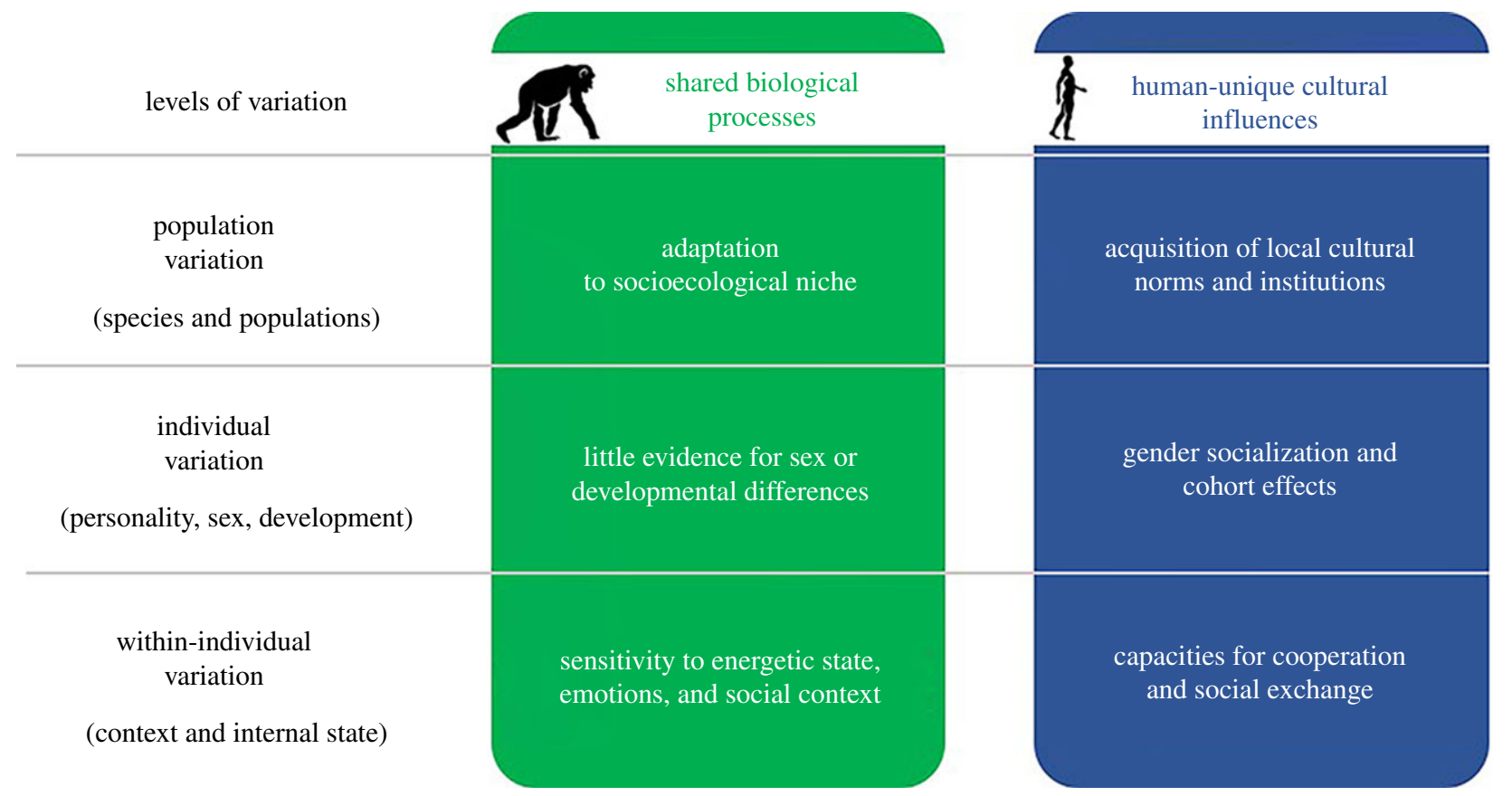

Figure 2. The origins of human variation in human economic behaviour. Comparative studies of other primates can help disentangle the relative role of shared biological processes versus human-unique cultural influences in risk preferences. Current evidence for variation across populations, individuals and contexts in primates suggests some processes are shared with humans whereas others are human-unique. (Online version in colour.)

game [110], the stag-hunt game [111] and the trust game $[112,113]$. In the modified trust game, chimpanzees could choose between obtaining a small but safe reward, or sending a larger reward to a partner who could then either reciprocate and send back a higher value reward or not. Chimpanzees will accept the social risk associated with trusting their partner [112] —especially when the partner is a close friend [113]. This suggests that a basic sensitivity towards degrees of social uncertainty may be shared with other primates. Yet a key question is, therefore, whether humans have special abilities to monitor social risk to thereby protect against free riders, given the greater scope of cooperation and reciprocity seen in humans $[104,114]$ and the importance of social risktaking in human economic systems [115]. For example, other primates may not be as proficient at dealing with risk imposed by exchanges because they cannot make formal agreements or enforce reciprocation. This highlights how both novel cognitive capacities (for engaging in cooperation) as well as humanspecific cultural norms for these interactions may re-shape human social risk preferences compared with other species.

\section{Conclusion: primate decision-making and human economic origins}

Humans exhibit great variation in responses to risk across populations, individuals and contexts, so understanding the origins of this variation is crucial to explaining patterns of human economic behaviour. We have argued that comparative studies of decision-making can disentangle the mechanisms and the function of this variation to address questions about both the proximate mechanisms and the ultimate consequences of these decision-making patterns. As such, non-human primates provide a complementary line of evidence to test hypotheses about the origins of human economic behaviours (figure 2).
We found that non-humans sometimes show patterns of variation like those in humans. For example, emotional states, social context and some neurotransmitter systems can modulate risk preferences in primates like in humans. This suggests that at least some of the proximate psychological mechanisms driving human economic behaviour build upon cognitive, emotional and neurobiological substrates that are shared with other primates Yet other mechanisms may be more specific to humans: while humans show robust gender differences in risk preferences as well as developmental change over the life-course, there is limited evidence for parallel shifts in non-human risky choice. This suggests that this variation may stem more from humanspecific mechanisms, such as cultural learning and socialization. Given that culturally based traits are more malleable and thus more amenable to interventions, this provides new clues for promoting optimal economic behaviour in humans.

A second question concerns the ultimate consequences of variation in risk preferences. Here, comparative work can provide an important line of evidence to test the adaptive consequences of different strategies. For example, there are robust species differences in responses to risk indicating that species that typically feed on more variable, heterogeneous resources are relatively more risk-seeking. Yet there are also crucial differences in human and animal patterns that may stem from humans' novel socioecological niche. Human hunter-gatherer lifestyles are characterized by a dependence on high-value and high-risk foods that may have required new social mechanisms to cope with a greater variability in foraging, such as food sharing and resource redistribution $[107,116]$. As a consequence, humans might have evolved new cognitive abilities and innovated new cultural practices to deal with the social risks presented by exchanges.

Yet there is still much work to be done. First, different species and questions have sometimes been tested using different tasks (figure 1), limiting some inferences across studies. In 
addition, primate studies, in general, are often limited by small sample sizes, especially with respect to questions of intraindividual variation. As such, comparisons of decisionmaking using standardized methods in larger populations with wider variation in sex, ages or particular life experiences are crucial to test these ideas. Finally, the animal choice typically involves biologically relevant rewards, but there is increasing evidence that people can be more risk-seeking when making 'foraging' decisions about food than in equivalent decisions involving money [67,103]. Given that humans engage in evolutionarily novel forms of economic exchange involving abstract currencies, but other primates can be trained to use and exchange tokens in specific contexts [84], animals thus present untapped opportunities to test how experience with markets impacts economic decision-making. More generally, comparative research is well-positioned to advance our understanding of human economic behaviour by pinpointing the necessary cognitive and experiential prerequisites that enable different aspects of decision-making and exchange.

Data accessibility. This article has no additional data.

Authors' contributions. F.D.P. and A.G.R. wrote the paper together.

Competing interests. The authors declare that they have no conflict of interest.

Acknowledgements. F.D.P. is supported by the French Agence National de la Recherche (under the Investissement d'Avenir programme, ANR-17-EURE-0010) ANR Labex IAST. A.G.R. is supported by NSF grant nos 1944881, 1926653 and Sloan Foundation Fellowship grant no. FG-2019-12054.

\section{References}

1. Hsee CK, Weber EU. 1999 Cross-national differences in risk preference and lay predictions. J. Behav. Decis. Making 12, 165-179. (doi:10.1002/(SICI)10990771(199906)12:2<165::AID-BDM316>3.0.(0;2-N)

2. Rieger M0, Wang M, Hens T. 2015 Risk preferences around the world. Manage. Sci. 61, 637-648. (doi:10.1287/mnsc.2013.1869)

3. Kuznar L. 2001 Risk sensitivity and value among Andean pastoralists: measures, models, and empirical tests. Curr. Anthropol. 42, 432-440. (doi:10.1086/320483)

4. Henrich J, McElreath R. 2002 Are peasants riskaverse decision makers? Curr. Anthropol. 43, 172-181. (doi:10.1086/338291)

5. Amir $D$, Jordan MR, McAuliffe $K$, Valeggia $C R$, Sugiyama LS, Bribiescas RG, Snodgrass JJ, Dunham Y. 2019 The developmental origins of risk and time preferences across diverse societies. J. Exp. Psychol. Gen. 149, 650-661. (doi:10.1037/ xge0000675)

6. Croson R, Gneezy U. 2009 Gender differences in preferences. J. Econ. Lit. 47, 448-474. (doi:10.1257/ jel.47.2.448)

7. Charness G, Gneezy U. 2012 Strong evidence for gender differences in risk taking. J. Econ. Behav. Org. 83, 50-58. (doi:10.1016/j.jebo.2011.06.007)

8. Frey R, Pedroni A, Mata R, Rieskamp J, Hertwig R. 2017 Risk preference shares the psychometric structure of major psychological traits. Sci. Adv. 3, e1701381. (doi:10.1126/sciadv.1701381)

9. Dohmen T, Falk A, Huffman D, Sunde U, Schupp J, Wagner GG. 2011 Individual risk attitudes: measurement, determinants, and behavioral consequences. J. Eur. Econ. Assoc. 9, 522-550. (doi:10.1111/j.1542-4774.2011.01015.x)

10. Paulsen DJ, Platt ML, Huettel SA, Brannon EM. 2012 From risk-seeking to risk-averse: the development of economic risk preference from childhood to adulthood. Front. Psychol. 3, 313. (doi:10.3389/ fpsyg.2012.00313)

11. Schurer S. 2015 Lifecycle patterns in the socioeconomic gradient of risk preferences. J. Econ. Behav. Org. 119, 482-495. (doi:10.1016/j.jebo. 2015.09.024)
12. Mata R, Josef AK, Hertwig R. 2016 Propensity for risk taking across the life span and around the globe. Psychol. Sci. 27, 231-243. (doi:10.1177/ 0956797615617811)

13. Schildberg-Hörisch H. 2018 Are risk preferences stable? J. Econ. Perspect. 32, 135-154. (doi:10. 1257/jep.32.2.135)

14. Bault N, Coricelli G, Rustichini A. 2008 Interdependent utilities: how social ranking affects choice behavior. PLOS ONE 3, e3477. (doi:10.1371/ journal.pone.0003477)

15. Hill SE, Buss DM. 2010 Risk and relative social rank: positional concerns and risky shifts in probabilistic decision-making. Evol. Hum. Behav. 31, 219-226. (doi:10.1016/j.evolhumbehav. 2010.01.002)

16. Coricelli G, Dolan RJ, Sirigu A. 2007 Brain, emotion and decision making: the paradigmatic example of regret. Trends Cogn. Sci. 11, 258-265. (doi:10.1016/ j.tics.2007.04.003)

17. Lerner JS, Li Y, Valdesolo P, Kassam KS. 2015 Emotion and decision making. Annu. Rev. Psychol. 66, 799-823. (doi:10.1146/annurev-psych-010213115043)

18. Kandasamy N, Hardy B, Page L, Schaffner M, Graggaber J, Powlson AS, Fletcher PC, Gurnell M, Coates J. 2014 Cortisol shifts financial risk preferences. Proc. Natl Acad. Sci. USA 111, 3608-3613. (doi:10.1073/pnas.1317908111)

19. Apicella CL, Carré JM, Dreber A. 2015 Testosterone and economic risk taking: a review. Adapt. Hum. Behav. Physiol. 1, 358-385. (doi:10. 1007/s40750-014-0020-2)

20. Amir D, Jordan MR. 2017 The behavioral constellation of deprivation may be best understood as risk management. Behav. Brain Sci. 40, E316. (doi:10.1017/S0140525X17000875)

21. Becker A, Enke B, Falk A. 2015 The ancient origins of the cross-country heterogeneity in risk preferences. Stanford Institute for Theoretical Economics (SITE), Department of Economics, Stanford. August 7. See https://www.cens.uni-bonn. de/team/associated-members/armin-falk/falk-risksent.pdf.
22. Cesarini $D$, Dawes $C T$, Johannesson $M$, Lichtenstein P, Wallace B. 2009 Genetic variation in preferences for giving and risk taking. Q. J. Econ. 124, 809-842. (doi:10.1162/qjec.2009.124.2.809)

23. Zhong S, Chew SH, Set E, Zhang J, Xue H, Sham PC, Ebstein RP, Israel S. 2009 The heritability of attitude toward economic risk. Twin Res. Hum. Genet. 12, 103-107. (doi:10.1375/twin.12.1.103)

24. Carpenter JP, Garcia JR, Lum JK. 2011 Dopamine receptor genes predict risk preferences, time preferences, and related economic choices. J. Risk Uncertain. 42, 233-261. (doi:10.1007/s11166-011-9115-3)

25. Hartley CA, Somerville LH. 2015 The neuroscience of adolescent decision-making. Curr. Opin. Behav. Sci. 5, 108-115. (doi:10.1016/j.cobeha.2015.09.004)

26. Galvan A, Hare T, Voss H, Glover G, Casey BJ. 2007 Risktaking and the adolescent brain: who is at risk? Dev. Sci. 10, F8-F14. (doi:10.1111/j.1467-7687.2006.00579.x)

27. Bolla KI, Eldreth DA, Matochik JA, Cadet JL. 2004 Sex-related differences in a gambling task and its neurological correlates. Cereb. Cortex 14, 1226-1232. (doi:10.1093/cercor/bhh083)

28. Cazzell M, Li L, Lin ZJ, Patel SJ, Liu H. 2012 Comparison of neural correlates of risk decision making between genders: an exploratory fNIRS study of the Balloon Analogue Risk Task (BART). Neuroimage 62, 1896-1911. (doi:10.1016/j. neuroimage.2012.05.030)

29. Ofek H. 2001 Second nature: economic origins of human evolution. Cambridge, UK: Cambridge University Press.

30. Knight FH. 1921 Risk, uncertainty, and profit. New York, NY: Houghton Mifflin.

31. Santos LR, Hughes KD. 2009 Economic cognition in humans and animals: the search for core mechanisms. Curr. Opin. Neurobiol. 19, 63-66. (doi:10.1016/j.conb.2009.05.005)

32. Platt ML, Huettel SA. 2008 Risky business: the neuroeconomics of decision making under uncertainty. Nat. Neurosci. 11, 398-403. (doi:10.1038/nn2062)

33. Rosati AG, Arre AM, Platt ML, Santos LR. 2016 Rhesus monkeys show human-like changes in gaze following across the lifespan. Proc. R. Soc. B 283, 20160376. (doi:10.1098/rspb.2016.0376) 
34. Key C, Ross C. 1999 Sex differences in energy expenditure in non-human primates. Proc. $R$. Soc. Lond. B 266, 2479-2485. (doi:10.1098/rspb. 1999.0949)

35. Leigh SR. 2004 Brain growth, life history, and cognition in primate and human evolution. Am. J. Primatol. 62, 139-164. (doi:10.1002/ ajp.20012)

36. Franklin MS, Kraemer GW, Shelton SE, Baker E, Kalin NH, Uno H. 2000 Gender differences in brain volume and size of corpus callosum and amygdala of rhesus monkey measured from MRI images. Brain Res. 852, 263-267. (doi:10.1016/S00068993(99)02093-4)

37. Kahneman D, Tversky A (eds). 2000 Choices, values, and frames. New York, NY: Cambridge University Press.

38. Weber EU, Johnson EJ. 2008 Decisions under uncertainty: psychological, economic, and neuroeconomic explanations of risk preference. In Neuroeconomics: decision making and the brain (eds PW Glimscher, CF Camerer, E Fehr, RA Poldrack), pp. 127-144. London, UK: Academic Press.

39. Stephens DW, Krebs JR. 1986 Foraging theory. Princeton, NJ: Princeton University Press.

40. Caraco T, Martindale S, Whittam TS. 1980 An empirical demonstration of risk-sensitive foraging preferences. Anim. Behav. 28, 820-830. (doi:10. 1016/S0003-3472(80)80142-4)

41. Kacelnik A, El Mouden C. 2013 Triumphs and trials of the risk paradigm. Anim. Behav. 86, 1117-1129. (doi:10.1016/j.anbehav.2013.09.034)

42. Mishra S. 2014 Decision-making under risk: integrating perspectives from biology, economics, and psychology. Pers. Soc. Psychol. Rev. 18, 280-307. (doi:10.1177/1088868314530517)

43. Fawcett TW, Fallenstein $B$, Higginson AD, Houston Al, Mallpress DE, Trimmer PC, Modelling Animal Decisions Group. 2014 The evolution of decision rules in complex environments. Trends Cogn. Sci. 18, 153-161. (doi:10.1016/j.tics.2013.12.012)

44. Holt CA, Laury SK. 2014. Assessment and estimation of risk preferences. In Handbook of the economics of risk and uncertainty (eds M Machina, WK Viscusi), pp. 135-201. Amsterdam, The Netherlands: Elsevier.

45. Levy DJ, Thavikulwat AC, Glimcher PW. 2013 State dependent valuation: the effect of deprivation on risk preferences. PLOS ONE 8, e53978. (doi:10.1371/ journal.pone.0053978)

46. Gilby IC, Wrangham RW. 2007 Risk-prone hunting by chimpanzees (Pan troglodytes schweinfurthii) increases during periods of high diet quality. Behav. Ecol. Sociobiol. 61, 1771-1779. (doi:10.1007/ s00265-007-0410-6)

47. Hertwig R, Erev I. 2009 The description-experience gap in risky choice. Trends Cogn. Sci. 13, 517-523. (doi:10.1016/j.tics.2009.09.004)

48. Beshears J, Choi JJ, Laibson D, Madrian BC. 2008 How are preferences revealed? J. Public Econ. 92, 1787-1794. (doi:10.1016/j.jpubeco.2008.04.010)
49. Kacelnik A, Bateson M. 1996 Risky theories - the effects of variance on foraging decisions. Am. Zool. 36, 402-434. (doi:10.1093/icb/36.4.402)

50. Heilbronner SR, Rosati AG, Stevens JR, Hare B, Hauser MD. 2008 A fruit in the hand or two in the bush? Divergent risk preferences in chimpanzees and bonobos. Biol. Lett. 4, 246-249. (doi:10.1098/ rsbl.2008.0081)

51. McCoy AN, Platt ML. 2005 Risk-sensitive neurons in macaque posterior cingulate cortex. Nat. Neurosci. 8 , 1220-1227. (doi:10.1038/nn1523)

52. Hayden BY, Platt ML. 2007 Temporal discounting predicts risk sensitivity in rhesus macaques. Curr. Biol. 17, 49-53. (doi:10.1016/j.cub.2006.10.055)

53. Long $A B$, Kuhn CM, Platt ML. 2009 Serotonin shapes risky decision making in monkeys. Soc. Cogn. Affect. Neurosci. 4, 346-356. (doi:10.1093/scan/nsp020)

54. Hayden B, Heilbronner S, Platt M. 2010 Ambiguity aversion in rhesus macaques. Front. Neurosci. 4, 166. (doi:10.3389/fnins.2010.00166)

55. Yamada H, Tymula A, Louie K, Glimcher PW. 2013 Thirst-dependent risk preferences in monkeys identify a primitive form of wealth. Proc. Natl Acad. Sci. USA 110, 15 788-15 793. (doi:10.1073/pnas.1308718110)

56. De Petrillo F, Ventricelli M, Ponsi G, Addessi E. 2015 Do tufted capuchin monkeys play the odds? Flexible risk preferences in Sapajus spp. Anim. Cogn. 18, 119-130. (doi:10.1007/s10071-014-0783-7)

57. MacLean EL, Mandalaywala TM, Brannon EM. 2012 Variance-sensitive choice in lemurs: constancy trumps quantity. Anim. Cogn. 15, 15-25. (doi:10. 1007/s10071-011-0425-2)

58. Proctor D, Williamson RA, Latzman RD, de Waal FB, Brosnan SF. 2014 Gambling primates: reactions to a modified lowa Gambling Task in humans, chimpanzees and capuchin monkeys. Anim. Cogn. 17, 983-995. (doi:10.1007/s10071-014-0730-7)

59. Leinwand JG, Huskisson SM, Egelkamp CL, Hopper LM. 2020 Within-and between-species variation in the responses of three primate species to a touchscreen gambling task. Learn. Motiv. 71, 101635. (doi:10.1016/j.Imot.2020.101635)

60. Hayden BY, Platt ML. 2009 Gambling for Gatorade: risk-sensitive decision making for fluid rewards in humans. Anim. Cogn. 12, 201-207. (doi:10.1007/ s10071-008-0186-8)

61. Rosati AG, Hare B. 2011 Chimpanzees and bonobos distinguish between risk and ambiguity. Biol. Lett. 7, 15-18. (doi:10.1098/rsbl.2010.0927)

62. Rosati AG, Hare B. 2012 Decision making across social contexts: competition increases preferences for risk in chimpanzees and bonobos. Anim. Behav. 84, 869-879. (doi:10.1016/j.anbehav.2012.07.010)

63. Rosati AG, Hare B. 2013 Chimpanzees and bonobos exhibit emotional responses to decision outcomes. PLOS ONE 8, e63058. (doi:10.1371/journal.pone. 0063058)

64. Haun DB, Nawroth C, Call J. 2011 Great apes' risktaking strategies in a decision-making task. PLOS ONE 6, e28801. (doi:10.1371/journal.pone.0028801)

65. Rivière J, Stomp M, Augustin E, Lemasson A, BloisHeulin C. 2018 Decision-making under risk of gain in young children and mangabey monkeys. Dev. Psychobiol. 60, 176-186. (doi:10.1002/dev.21592)

66. Rivière J, Kurt A, Meunier H. 2019 Choice under risk of gain in tufted capuchin monkeys (Sapajus apella): a comparison with young children (Homo sapiens) and mangabey monkeys (Cercocebus torquatus torquatus). J. Neurosci. Psychol. Econ. 12, 159-168. (doi:10.1037/npe0000109)

67. Rosati AG, Hare B. 2016 Reward currency modulates human risk preferences. Evol. Hum. Behav. 37, 159-168. (doi:10.1016/j.evolhumbehav. 2015.10.003)

68. Steelandt S, Broihanne MH, Thierry B. 2011 Are monkeys sensitive to the regularity of pay-off? Int. J. Comp. Psychol. 24, 272-283.

69. Pelé M, Broihanne MH, Thierry B, Call J, Dufour V. 2014 To bet or not to bet? Decision-making under risk in non-human primates. J. Risk Uncertain. 49 141-166. (doi:10.1007/s11166-014-9202-3)

70. Broihanne $M H$, Romain A, Call J, Thierry B, Wascher CA, De Marco A, Verrier D, Dufour V. 2019 Monkeys (Sapajus apella and Macaca tonkeana) and great apes (Gorilla gorilla, Pongo abelii, Pan paniscus, and Pan troglodytes) play for the highest bid. J. Comp. Psychol. 133, 301. (doi:10.1037/com0000153)

71. Lakshminarayanan VR, Chen MK, Santos LR. 2011 The evolution of decision-making under risk: framing effects in monkey risk preferences. J. Exp. Soc. Psychol. 47, 689-693. (doi:10.1016/j.jesp.2010. 12.011)

72. Chen MK, Lakshminarayanan VR, Santos LR. 2006 How basic are behavioral biases? Evidence from capuchin monkey trading behavior. J. Polit. Econ. 114, 517-537. (doi:10.1086/503550)

73. MacLean EL et al. 2012 How does cognition evolve? Phylogenetic comparative psychology. Anim. Cogn. 15, 223-238. (doi:10.1007/s10071-011-0448-8)

74. Beran MJ. 2017 Quantitative cognition. In APA handbook of comparative psychology: perception, learning, and cognition (ed. J Call), pp. 535-577. Washington, DC: American Psychological Association.

75. Rakoczy H, Clüver A, Saucke L, Stoffregen N, Gräbener A, Migura J, Call J. 2014 Apes are intuitive statisticians. Cognition 131, 60-68. (doi:10.1016/j. cognition.2013.12.011)

76. Tecwyn EC, Denison S, Messer E, Buchsbaum D. 2017 Intuitive probabilistic inference in capuchin monkeys. Anim. Cogn. 20, 243-256. (doi:10.1007/ s10071-016-1043-9)

77. De Petrillo F, Rosati AG. 2019 Rhesus macaques use probabilities to predict future events. Evol. Hum. Behav. 40, 436-446. (doi:10.1016/j.evolhumbehav. 2019.05.006)

78. Rosati AG. 2017 Foraging cognition: reviving the ecological intelligence hypothesis. Trends Cogn. Sci. 21, 691-702. (doi:10.1016/j.tics.2017.05.011)

79. Knott CD. 2005 Energetic responses of food availability in the great apes; implications for hominin evolution. In Seasonality in primates: studies of living and extinct human and nonhuman primates (eds DK Brockman, (P van Schaik), 
pp. 351-378. Cambridge, UK: Cambridge University Press.

80. Koops K, Visalberghi E, van Schaik CP. 2014 The ecology of primate material culture. Biol. Lett. 10, 20140508. (doi:10.1098/rsbl.2014.0508)

81. Rogers ME, Abernethy $K$, Bermejo M, Cipolletta C, Doran D, McFarland K, Nishihara T, Remis M, Tutin CE. 2004 Western gorilla diet: a synthesis from six sites. Am. J. Primatol. 64, 173-192. (doi:10.1002/ ajp.20071)

82. De Petrillo F, Rosati AG. 2019 Ecological rationality: convergent decision-making in apes and capuchins. Behav. Process. 164, 201-213. (doi:10.1016/j. beproc.2019.05.010)

83. Addessi E, Paglieri F, Beran MJ, Evans TA, Macchitella L, De Petrillo F, Focaroli V. 2013 Delay choice versus delay maintenance: different measures of delayed gratification in capuchin monkeys (Cebus apella). J. Comp. Psychol. 127, 392-398. (doi:10. 1037/a0031869)

84. De Petrillo F, Caroli M, Gori E, Micucci A, Gastaldi S, Bourgeois-Gironde S, Addessi E. 2019 Evolutionary origins of money categorization and exchange: an experimental investigation in tufted capuchin monkeys (Sapajus spp.). Anim. Cog. 22, 169-186. (doi:10.1007/s10071-018-01233-2)

85. Zuckerman M. 2007 Sensation seeking and risky behavior. Washington, DC: American Psychological Association.

86. Mishra S, Lalumière ML. 2011 Individual differences in risk-propensity: associations between personality and behavioral measures of risk. Pers. Individ. Differ. 50, 869-873. (doi:10.1016/j.paid. 2010.11.037)

87. Lucarelli M et al. 2017 Polymorphism of the 3'-UTR of the dopamine transporter gene (DAT) in New World monkeys. Primates 58, 169-178. (doi:10. 1007/s10329-016-0560-0)

88. Rosati AG, DiNicola LM, Buckholtz JW. 2018 Chimpanzee cooperation is fast and independent from self-control. Psychol. Sci. 29, 1832-1845. (doi:10.1177/0956797618800042)

89. Lonsdorf EV. 2017 Sex differences in nonhuman primate behavioral development. J. Neurosci. Res. 95, 213-221. (doi:10.1002/jnr.23862)

90. Gilby IC et al. 2017 Predation by female chimpanzees: toward an understanding of sex differences in meat acquisition in the last common ancestor of Pan and Homo. J. Hum. Evol. 110, 82-94. (doi:10.1016/j.jhevol.2017.06.015)
91. Fragaszy DM, Visalberghi E, Fedigan LM. 2004 The complete capuchin: the biology of the genus Cebus. Cambridge, UK: Cambridge University Press.

92. Krupenye C, Rosati AG, Hare B. 2015 Bonobos and chimpanzees exhibit human-like framing effects. Biol. Lett. 11, 20140527. (doi:10.1098/rsbl.2014. 0527)

93. Addessi E, Paglieri F, Focaroli V. 2011 The ecological rationality of delay tolerance: insights from capuchin monkeys. Cognition 119, 142-147. (doi:10.1016/j. cognition.2010.10.021)

94. Herrmann E, Hare B, Call J, Tomasello M. 2010 Differences in the cognitive skills of bonobos and chimpanzees. PLoS ONE 5, e12438. (doi:10.1371/ journal.pone.0012438)

95. Wobber V, Herrmann E. 2015 The influence of testosterone on cognitive performance in bonobos and chimpanzees. Behaviour 152, 407-423. (doi:10. 1163/1568539X-00003202)

96. Samanez-Larkin G, Knutson B. 2015 Decision making in the ageing brain: changes in affective and motivational circuits. Nat. Rev. Neurosci. 16, 278-289. (doi:10.1038/nrn3917)

97. Malmendier U, Nagel S. 2011 Depression babies: do macroeconomic experiences affect risk taking? Q. J. Econ. 126, 373-416. (doi:10.1093/qje/qjq004)

98. Jianakoplos NA, Bernasek A. 2006 Financial risk taking by age and birth cohort. South. Econ. J. 72, 981-1001. (doi:10.2307/20111864)

99. Jones JH. 2011 Primates and the evolution of long, slow life histories. Curr. Biol. 21, R708-R717. (doi:10.1016/j.cub.2011.08.025)

100. Rosati AG, Hare B. 2012 Chimpanzees and bonobos exhibit divergent spatial memory development. Dev. Sci. 15, 840-853. (doi:10.1111/j.1467-7687.2012. 01182.x)

101. De Petrillo F, Tonachella G, Addessi E. 2017 Emotional correlates of probabilistic decision making in tufted capuchin monkeys (Sapajus spp.). Anim. Behav. 129, 249-256. (doi:10.1016/j.anbehav.2017. 06.001)

102. Lee PC. 2009 Endocrinology of social relationships. Cambridge, MA: Harvard University Press.

103. De Petrillo F, Paoletti M, Bellagamba F, Manzi G, Paglieri F, Addessi E. 2020 Contextual factors modulate risk preferences in adult humans. Behav. Process. 176, 104137. (doi:10.1016/j.beproc.2020. 104137)

104. Melis AP, Warneken F. 2016 The psychology of cooperation: insights from chimpanzees and children. Evol. Anthropol. 25, 297-305. (doi:10. 1002/evan.21507)

105. Bohnet I, Greig F, Herrmann B, Zeckhauser R. 2008 Betrayal aversion: evidence from Brazil, China, Oman, Switzerland, Turkey, and the United States. Am. Econ. Rev. 98, 294-310. (doi:10.1257/aer.98. 1.294)

106. Rilling JK, King-Casas B, Sanfey AG. 2008 The neurobiology of social decision-making. Curr. Opin. Neurobiol. 18, 159-165. (doi:10.1016/j.conb.2008. 06.003)

107. Kaplan HS, Schniter E, Smith VL, Wilson BJ. 2012 Risk and the evolution of human exchange. Proc. R. Soc. B 279, 2930-2935. (doi:10.1098/rspb. 2011.2614)

108. Zoratto F, Oddi G, Gori E, Micucci A, De Petrillo F, Paglieri F, Adriani W, Laviola G, Addessi E. 2018 Social modulation of risky decision-making in rats (Rattus norvegicus) and tufted capuchin monkeys (Sapajus spp.). Behav. Brain Res. 347, 37-48. (doi:10.1016/j.bbr.2018.02.033)

109. Calcutt SE, Proctor D, Berman SM, de Waal FB. 2019 Chimpanzees (Pan troglodytes) are more averse to social than nonsocial risk. Psychol. Sci. 30, 105-115. (doi:10.1177/ 0956797618811877)

110. Jensen K, Call J, Tomasello M. 2007 Chimpanzees are rational maximizers in an ultimatum game. Science 318, 107-109. (doi:10.1126/science. 1145850)

111. Bullinger AF, Wyman E, Melis AP, Tomasello M. 2011 Coordination of chimpanzees (Pan troglodytes) in a stag hunt game. Int. J. Primatol. 32, 1296-1310. (doi:10.1007/s10764-011-9546-3)

112. Engelmann JM, Herrmann E, Tomasello M. 2015 Chimpanzees trust conspecifics to engage in lowcost reciprocity. Proc. R. Soc. B 282, 20142803. (doi:10.1098/rspb.2014.2803)

113. Engelmann JM, Herrmann E. 2016 Chimpanzees trust their friends. Curr. Biol. 26, 252-256. (doi:10. 1016/j.cub.2015.11.037)

114. Warneken F. 2018 How children solve the two challenges of cooperation. Annu. Rev. Psychol. 69, 205-229. (doi:10.1146/annurev-psych-122216011813)

115. Fukuyama F. 1995 Trust: the social virtues and the creation of prosperity. New York, NY: Free Press.

116. Jaeggi AV, Gurven M. 2013 Natural cooperators: food sharing in humans and other primates. Evol. Anthropol. 22, 186-195. (doi:10.1002/evan.21364) 